\title{
PARA QUE SERVE O ENSINO DE HISTÓRIA?*
}

\author{
PARA QUE SIRVE LA ENSEÑANZA DE HISTORIA
}

\author{
Josep Fontana $^{* *}$ \\ Tradução \\ Sheille Soares de Freitas (Unioeste) \\ Revisão \\ Ângela Meirelles de Oliveira
}

RESUMO: A tradução que apresento a seguir traz aspectos importantes da concepção de história e da trajetória combativa de Fontana, a qual consolidou sua prática e produção acadêmica. Ao retomar essa conferência, doze anos após sua realização, faço isso por reconhecer sua pertinência, quando não urgência, ao tratar da "função social da história", ao discutir as "guerras" pelos usos da história e das memórias, bem como ao destacar a relevância de nossa intromissão nessa história ensinada, ao disputar alternativas para construir, o que ele mesmo denominou, como "história de todos". Tudo isso, enfatizando o necessário estímulo "ao pensar por si mesmo" na análise histórica, vendo essa postura como o uma prática importante na construção da consciência social e de nossa intervenção no presente.

PALAVRAS-CHAVE: ensino de história; usos da história; papel da(o) profissional de história

\footnotetext{
* Conforme nota do editor, expressa na versão publicada originalmente em 2009, essa conferência foi realizada em 24 de outubro de 2008, no contexto da VIII Jornada de Encuentro y Debate de la Escuela de Educación de la Universidad de Viña del Mar, em Valparaíso-Chile. Essa atividade contou com a presença de Josep Fontana entre os dias 21 e 25 de outubro desse ano. Essa participação resultou em uma publicação de Fontana, intitulada: "La historia que se piensa: Conferencias, clases y conversaciones en Chile”. Valparaiso: Colección Historia Vital/Ediciones Escaparate, 2009. A obra conta com edição e introdução de Pablo Aravena Nuñez, Professor da Universidad de Valparaíso. Agradeço a gentileza do Prof. Pablo Aravena Nuñez, assim como da Ediciones Escaparate, pela liberação do texto para publicarmos sua tradução no Brasil.

** Historiador catalão, falecido em 2018, aos 86 anos. Com várias obras publicadas sobre temporalidades específicas da história, Fontana não se absteve de apresentar suas posições políticas e a influência da tradição marxista nos debates que promovia. Em particular, destaco a relevância de suas colocações acerca do Franquismo e da Prática historiográfica. Conforme definição, muito bem colocada por Aravena Nuñez, Fontana defendia o livre debate e o livre acesso e análise histórica, portanto, que saibamos tomar como estímulo seus incômodos e princípios.
} 
"a história vai ao passado porque se preocupa com o presente. Esta é a verdadeira pedreira da qual ela [história] extrai seus problemas - e não meras curiosidades". Pablo Aravena Nuñez apud Fontana (2009)

Para que serve o ensino de história? Em resposta a esta pergunta convém que reflitamos por um momento acerca da natureza e da função da memória, que é o território em que se desenvolve o trabalho do historiador. A memória pessoal é o componente fundamental de nossa identidade como indivíduos, o que nos faz sermos nós mesmos e não os outros. Isso vale, em outra escala, para aquela memória coletiva que é, ou que procura tornar-se, a história, cuja função é expressar a identidade de um grupo. Dizia um historiador norte-americano recentemente falecido, Arthur Schlessinger Jr.: "A história é para a nação como a memória para o indivíduo. Assim como uma pessoa privada de memória vaga desorientada e perdida, sem saber de onde vem ou para onde vai, uma nação à qual é negada uma concepção de seu passado será impotente para enfrentar o seu presente e o seu futuro".

Mas, o problema é aqui mais complexo do que no caso da memória pessoal, porque essa memória social deveria refletir uma pluralidade de experiências, deveria ser capaz de escutar e harmonizar as diversas vozes que integram esse grupo. Ocorre que, geralmente, a definição dessa identidade, muitas vezes, insere-se no domínio do que chamamos de uso público da história, o que um historiador italiano descreveu como

tudo aquilo que não entra diretamente na história profissional, mas constitui a memória pública [...]; tudo aquilo que cria o discurso histórico difuso, a visão de história, consciente ou inconsciente, que é própria de todos os cidadãos. Algo no qual historiadores desempenham um papel, porém é orientado, substancialmente, por outros protagonistas políticos e pelos meios de comunicação de massas. ${ }^{1}$

A historiografia acadêmica parece ter como objeto central legitimar, retrospectivamente, as atuações estatais do presente e a estrutura de poder social

\footnotetext{
${ }^{1}$ SANTOMASSIMO, Gianpasquale. "Guerra e legitimazione storica”, em: Passato e presente, (Florencia) n 54 (settembre-dicembre 2001), pp. 5-23 (citadas as páginas 8-9).
} 
de nosso tempo, ou seja, a ordem estabelecida. Escolhe para isso, como objetos dignos de estudo, como "fatos históricos", os que se referem à história do Estado e elege como protagonistas os seus dirigentes. Uma história, portanto, onde estão ausentes os demais, aqueles que não são governantes nem personagens principais destacados. A alternativa seria construir um tipo de história que permita escutar as várias vozes da sociedade e, não somente, dos dirigentes; que reconheça grupos subalternos que até o momento têm ficado à margem da narrativa central, como é o caso das mulheres.

Mas isso não é o que se espera de quem ensina história. Pelo contrário, os governos sempre estiveram cientes da importância de controlar o uso público da história. Em um passado mais distante, nomeavam cronistas oficiais (Luis XIV, na França, tinha até 19 historiadores em seus registros de pagamentos), ou controlavam a forma como se recordava os acontecimentos: Napoleão se encarregava de averiguar todos os detalhes dos quadros que reproduziam suas vitórias.

Essa preocupação aumentou consideravelmente e tomou um novo sentido, a partir do século XIX, com a formação dos Estados Nacionais Modernos. Os governos decidiram vigiar firmemente os conteúdos que eram ensinados, "porque essa coisa de história", como disseram tanto a senhora Thatcher como Nikita Krushchev, que ao menos nisso coincidiam, é uma questão demasiado importante para ser deixada sem vigilância nas mãos de quem se dedica a ensinar. A história que os governos impunham devia cumprir a dupla função de legitimar cada Estado-nação, construindo uma visão que amenize as crises e dissidências que ocorreram ao longo de seu desenvolvimento e, ao mesmo tempo, consolide a aceitação dos valores estabelecidos, difundindo uma determinada concepção da ordem social.

Isso é o que garantia a presença da história no ensino. Quando nos anos 80 do século XX houve impulsos de substitui-la por outras disciplinas sociais ou por métodos destinados a desenvolver outras habilidades, tanto o governo socialista francês como o conservador britânico retificaram imediatamente a permanência do ensino de história, frente ao risco de perder o mais eficaz 
instrumento de ensino do patriotismo. Uma preocupação que levou Christopher Hill a dizer que quando os políticos "começam a falar de inculcar patriotismo no ensino de história na escola, devemos nos congratular por esse interesse, mas nos preocupar com suas intenções".

A França chegou ao ponto de publicar leis que estabelecem certos conteúdos acerca de uma série de questões históricas, tornando crime afastar-se da ortodoxia estabelecida: em 1990 houve a lei sobre o Holocausto, em 2001 outras duas leis sobre o genocídio armênio e sobre o tráfico negreiro e em 2005 uma lei para que se reconhecesse o papel positivo da colonização francesa. Tudo isso culminou com a proposta de Sarkozy de criar um ministério que teve entre seus objetivos a "identidade nacional". 2

Em outros casos, sequer foi necessário que o Estado agisse, sendo que os mesmos efeitos são alcançados por pressão social. James W. Loewen explica em Las mentiras que me contó mi maestro como os livros didáticos atuais norte-americanos manipulam o que se refere à guerra do Vietnã, e nos diz que os professores temem se envolver em controvérsias sobre essas questões por receio de serem demitidos. São os próprios pais os que exercem a vigilância intelectual sobre a escola: exigem que não se ensine a seus filhos sobre o evolucionismo, no campo da ciência, e os que zelam para que, no que se refere à história, sejam aplicados critérios de "puro americanismo", de "meu país, com razão ou sem ela". 3

Por que esse medo em relação ao que se pode aprender na escola acerca de temas como a guerra do Vietnã? Não é tanto porque se possam difundir conteúdos antipatrióticos, o qual não é provável, mas pelo risco de que os alunos possam pensar por si mesmos. Se assim fizessem, poderiam descobrir que nessa guerra, que acabou em 1975, ganharam os "maus", e então se observaria que não ocorreu nenhum dos desastres com os quais se justificou o próprio confronto: não houve a temida operação dominó - nenhum outro país ficou sob o jugo de um regime comunista, como foi profetizado -, e não só não

\footnotetext{
${ }^{2}$ RÉMOND, René. Quand l'état se mêle de l'historia, París, Stock, 2006.

${ }^{3}$ LOEWEN, James W. Lies my teacher told me, New York, Touchstone, 1996.
} 
se produziu um retrocesso da civilização, como, desde então, o Vietnã unificado tem avançado por um caminho de prosperidade. A reflexão lógica a que os alunos poderiam chegar seria a de que aquela guerra, que custou aos norteamericanos 58 mil mortos e 300 mil feridos (e uma perda imensamente maior aos vietnamitas) e que teve um custo para os Estados Unidos de 140 milhões de dólares, com o que, segundo diz o Guia para o estudo da guerra do Vietnã da Universidade de Columbia ${ }^{4}$, "absorveu recursos que eram necessários para os serviços sociais", foi um erro estúpido dos dirigentes de seu país, engendrado pela ignorância e pelo medo. Está claro que a intenção é evitar que os alunos por meio do ensino de história acessem essas questões, pensando por sua conta; de outro modo, não teria como enganá-los novamente, para levá-los ao Iraque ou ao Afeganistão.

Assim, estamos passando do terreno da memória, como sinal de identidade, ao de outra de suas funções, ainda mais importante, se isso é possível. Um grande neurobiólogo, ganhador do prêmio Nobel de Medicina, Gerald Edelman, disse-nos que uma das funções essenciais da memória individual é a de nos permitir fazer uma espécie de reordenação construtiva de nossas recordações cada vez que enfrentamos uma experiência nova. Essa reelaboração não é uma simples reprodução de uma sequência anterior de acontecimentos, mas uma estratégia para avaliar as novas situações que temos que enfrentar, construindo (com os elementos que conservamos na memória, fruto de nossas experiências anteriores) um cenário onde possam ser integrados os novos dados que nos são apresentados, para elaborar o que Edelman chama de "presentes rememorados". Essa interação da nossa memória e das percepções que recebemos do exterior é precisamente o que fundamenta a consciência. ${ }^{5}$

\footnotetext{
${ }^{4}$ ANDERSON, David L. The Columbia guide to the Vietnam war. New York, Columbia University Press, 2022, p.78.

${ }^{5}$ EDELMAN, Gerald. M.; TONONI, Giulio. El universe de la conciencia. Cómo la materia se convierte en imaginación. Barcelona, Crítica, 2002 e EDELMAN, Gerald. M. Wider than the sky. A revolutionary view of consciousness. Londres, Penguin, 2005. De modo semelhante, FAUCONNIER, Gilles; TURNER, Mark. The way we think. Conceptual bending and the mind's hidden complexities. Nueva York, Basic Books, 2002, sinalizando a importância da "construção do irreal", mediante o uso de cenários contra factuais.
} 
Isso também vale sobre a memória coletiva, que é, ou que aspira a ser, a história. O valor fundamental da memória coletiva, como a individual, deveria ser o de nos proporcionar uma ferramenta de análise da realidade que nos rodeia, com a finalidade de nos ajudar a construir "presentes rememorados", com os quais poderíamos enfrentar os novos problemas que se apresentam para nós. Trata-se daquilo que meu professor Pierre Vilar chamava "pensar historicamente", que não queria dizer agarrar-se permanentemente ao passado, mas, pelo contrário, usar o aprendizado com o passado para tratar de compreender melhor o mundo em que vivemos.

Entendida assim a história, a nossa função ao ensiná-la a nossos alunos não deve ser para incutir certas verdades sobre o passado, mas para alimentar suas mentes, não só com elementos do conhecimento histórico para que possam operar com eles, mas, também, e eu diria sobretudo, com um sentido crítico que os leve a entender que são eles quem devem utilizar essa aprendizagem para avaliar o universo social que os rodeia (com a experiência adquirida, com os "presentes rememorados" que elaborarem), sem aceitar que lhes digam que o processo histórico é produto de uma evolução lógica, natural e inevitável.

Desse modo, nossos alunos serão capazes de aprender a analisar as notícias que lhes chegam diariamente por meios de comunicação, com um espírito crítico, ao invés de aceitá-las sem discussão, porque, frequentemente, o que se apresenta como um relato objetivo de acontecimentos vem envolto em um conjunto de clichês e pré-conceitos convenientes. Um ensino de história adequado deve servir, antes de tudo, para que aprendam a ver com outros olhos seu entorno social; para que aprendam a "pensar historicamente", posto que todos os fatos sociais que possam ser objeto de reflexão, incluindo aqueles contidos nos jornal de hoje, já se passaram e, portanto, são objetos potenciais da análise histórica.

Raphael Samuel escreveu, celebrando o pleno retorno do ensino de história na escola: "Como uma disciplina intelectual a história requer um grau de distanciamento: a habilidade de estabelecer contrastes e fazer conexões, de descobrir um princípio de ordem em meio a um caos aparente, de explicar, ou 
tratar de explicar, os porquês e as razões de fatos, aparentemente misteriosos, de pensar o impensável. Como uma forma de investigação, é uma viagem ao desconhecido. Como disciplina ensinada, supõe-se que amplia a mente, para desafiar as suposições admitidas na vida cotidiana, mostrando-nos a contingência de muito do que consideramos natural e permanente, a modernidade de muito do que equivocadamente supomos tradicional e a antiguidade de muito do que se passa por novo". 6

Recentemente, recebi uma mensagem de um antigo aluno, que havia cursado história na Universidade em que trabalhava no final dos anos 70 do século XX. Ele me contou que sua vida o havia levado para longe do campo da pesquisa ou do ensino de história, mas acrescentou: "Nunca me arrependi de cursar história, porque o que aprendi me permitiu ver as coisas mais claramente nestes anos obscuros. Muitas vezes, enquanto trabalhava em sindicatos ou participava de movimentos sociais, eu me recordava do que havia assimilado na faculdade e via como era útil".

Esse foi um dos momentos em que senti mais orgulho do meu ofício; muito mais do que ao receber prêmios ou distinções públicas por meu trabalho como investigador. Penso que o mais importante que realizei em minha profissão foi instigar alguns dos que passaram por minhas aulas a se nortear em meio à sociedade em que vivem e a pensar por si mesmos.

Para realizar esse trabalho de estimular as consciências, o professor de história tem dois privilégios. O primeiro, por ser o único que se ocupa globalmente de todas as dimensões do ser humano, desde suas necessidades vitais e seus trabalhos, até suas aspirações e seus sonhos. O segundo, porque a história é a única disciplina entre aquelas oferecidas na educação primária e secundária - ou seja, na educação que será recebida pelo maior número de cidadãos - que tem a capacidade de fomentar uma consciência crítica em relação ao universo social em que vivemos, tornando-a uma ferramenta eficaz

\footnotetext{
${ }^{6}$ SAMUEL, Raphael. The return of history. In: London Review of Books, 14 de junio de 1990, pp. 9-12.
} 
de educação cidadã ${ }^{7}$. Retomo a afirmação de Voltaire de que, uma vez que os homens tenham aprendido a pensar por si mesmos, não é mais possível tratá-los como gado: uma das missões essenciais do ensino de história é precisamente a de abrir os olhos dos seres humanos para que não se possa manejá-los como se fossem bois. Algo que, infelizmente, ainda acontece com frequência.

Não se trata, quero insistir nisso, de fixar e estabelecer um novo cânone contra as verdades históricas estabelecidas, mas de ensinar uma história entendida sobretudo como método, como instrumento de compreensão de nosso entorno e, por isso mesmo, em contínua transformação. O historiador não é o guardião eterno de um repertório de dados pré-estabelecidos sobre o passado, mas alguém que se ocupa em uma investigação aberta e dinâmica desse passado. Como escrevia Arthur Schlesinger Jr. (o qual citei no início dessa reflexão), em um artigo intitulado "Historia y estupidez nacional”, para aludir à forma como os norte-americanos estavam repetindo no Iraque erros do Vietnã, mencionou "As concepções de passado estão longe de serem estáveis, pois são constantemente revisadas de acordo com as urgências do presente. A história não é um livro pronto ou um veredito final. Está sempre em construção [...]. Quando surgem novas urgências em nosso tempo e em nossa vida, o historiador desloca seu foco, examinando as sombras, colocando em primeiro plano coisas que sempre estiveram ali, mas que os historiadores anteriores deixaram à margem da memória coletiva. Novas vozes emergem da obscuridade histórica e pedem nossa atenção". ${ }^{8}$

O papel daqueles de nós que ensinam história para auxiliar os alunos a desenvolver uma consciência crítica é muito mais importante do que geralmente pensamos. Marc Bloch entendeu isso nos últimos dias de sua vida, quando lutava na resistência contra os nazistas. Em momentos de tantas dificuldades,

\footnotetext{
${ }^{7}$ Para a tradução, consideramos essa expressão "educação cidadã" mais condizente com a visão de mundo e impressões professadas por Fontana ao longo de suas obras e ações, pois ela expressa uma noção que vai ao encontro de seu estímulo para nosso compromisso com uma história de todos, que cumpra sua função social no presente e na prospecção de ações em sociedade. (N. da T)

${ }^{8}$ SCHLESINGER JR., Arthur. Historia y estupidez nacional: de Andrew Jackson a George W. Bush. Claves de razón práctica, Madrid, n. 164, p. 38-41, 2006. (N. da T)
} 
que terminaram com seu assassinato nas mãos da GESTAPO ${ }^{9}$, Marc Bloch reivindicava a capacidade do historiador para ajudar a mudar as coisas. Uma consciência coletiva, escreveu, está formada por "uma multiplicidade de consciências individuais que influem incessantemente entre si”. Portanto, "formar uma ideia clara das necessidades sociais e esforçar-se para difundi-la significa fornecer um grão [de consciência crítica], que fermente na mentalidade comum, dando a oportunidade de modificá-la um pouco e, como consequência, alterar de alguma forma o curso dos acontecimentos, que são regidos, em última instância, pela mente dos homens". ${ }^{10}$

Penso em um ensino de história que aspire menos acumular conhecimento e mais ensinar a pensar, a duvidar, a conseguir que nossos alunos não aceitem os fatos que estão nos livros de história como se fossem dados que devem memorizar, ou certezas como as que se ensinam no estudo de exatas, mas que os vejam como opiniões e interpretações que se podem (e devem) analisar e discutir. Para que se acostumem a manter uma atitude parecida ante as supostas certezas que lhes são oferecidas diariamente nos meios de comunicação, domesticados e controlados. Como disse Bloch, o que temos que fazer é fornecer um grão desse propósito para que fermente na mente do estudante. Essa é a grande tarefa que penso que podemos realizar como professores de história.

Valparaiso, Outubro de 2008

Recebido em: 30 de agosto de 2020

Aceito em: 1 de dezembro de 2020

\footnotetext{
9 Abreviação para a identificação da polícia secreta do Estado alemão nazista (Geheim Staatspolizei), a qual foi autorizada, desde 1933, a espionar, prender e exterminar muitos daqueles que fossem considerados uma ameaça ao regime. (N. da T)

${ }^{10}$ BLOCH, Marc. La extraña derrota. Barcelona, Crítica, 2003, pp. 164-165.
} 